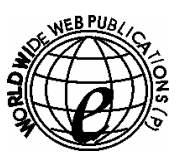

\title{
Extractive Spectrophotometric determination of Dimethoate in Environmental Samples with Azure-B
}

\author{
K. M. REDDY, ${ }^{1}$ and P. CHIRANJEEVI ${ }^{2 *}$ \\ ${ }^{1}$ Department of Chemistry, S. V. Arts College, Tirupati - 517502. \\ ${ }^{2 *}$ Environmental Monitoring Laboratories, Department of Chemistry, \\ S.V.University, Tirupati - 517 502, India.
}

Received 23 March 2005; Accepted 31 May 2005

\begin{abstract}
A new simple and selective spectrophotometric method is developed for the determination of dimethoate by using Azure-B is described. The method was based on the alkaline hydrolysis of dimethoate in presence of sodium ethoxide to form sodium dimethyl dithiophosphate (Na-DMDTP). The Na-DMDTP was formed as an ion-pair complex with cationic dye, azure-B. The ion-pair complex was extracted into chloroform. The color of the organic layer was measured at $535 \mathrm{~nm}$. The method was applied to the determination of dimethoate residues in water, grain and soil samples.
\end{abstract}

Key words: Dimethoate, Dimethyldithiophosphate (DMDTP), Azure-B, Spectro-photometry and Environmental samples.

\section{Introduction}

Dimethoate chemically known as (O, O-dimethyl-S-methyl carbomyl methyl phsphorodithioate) belongs to an organophosphorus pesticide, widely used against pests ${ }^{1}$ on crops like cotton, coffee, tea, tobacco, grapes and vegetables. It is used to control house flies around livestock pens, processing plants and human dewellings. Its toxic properties includes mutagenic, genotoxic and inhibitory affects on cholinesterase enzyme. ${ }^{2}$ The indiscriminate use of dimethoate for agricultural purpose, domestic purpose leads to contamination by atmospheric aerosols, fallout, water and soil. Hence it is inevitable to determine the residue of dimethoate in water bodies, soils and vegetables to check for health hazardous to human bodies.

Many methods have been developed for the determination of dimethoate such as colorimetry, ${ }^{3-5}$ polarography, ${ }^{6-7}$ HPLC, ${ }^{8}$ GC, ${ }^{9}$ TLC, ${ }^{10}$ spectrofluorometry ${ }^{11}$ and spectrophotometry. ${ }^{12}$ But these methods offer certain disadvantages such as less sensitivity, stability selectivity, high reagent consumption and interference of foreign species. Hence, it is desirable to develop a facile, rapid, accurate and sensitive spectrophotometric technique for the determination of dimethoate in environmental systems. 
Hence, the reported extractive spectrophotometry for the determination of dimethoate in its formulations and in various environmental samples is more sensitive than the previously reported method available in the literature. $^{10}$ Dimethoate was hydrolysed into sodium-dimethyl dithiophosphate [Na-DMDTP], extracted with cationic dye as an ion-pair-DMDTP into chloroform. The absorbance of organic layer was measured at $535 \mathrm{~nm}$ against reagent blank.

\section{Experimental}

Analytical grade reagents were used. Double distilled water was used throughout the experiments. All Chemicals were purchased from S.D fine Chemicals, Mumbai, India. Dimethoate $97.5 \%$ technical grade and $30 \%$ EC formulations was supplied by Ralli's Agrochemical Research Station, Bangalore, India.

A HITACHI U -2001 spectrophotometer with $1.0 \mathrm{~cm}$ matched quartz cell was employed to obtain electronic spectral measurements. An ELICO digital $\mathrm{pH}$ meter with combined glass electrode was used for the $\mathrm{pH}$ measurements.

\section{Solutions}

Standard dimethoate $0.4891 \mathrm{~g}$ of $97.5 \%$ technical grade solution was dissolved in $100 \mathrm{ml}$ carbontetrachloride. Working standard solutions were prepared by approximate dilution of the dimethoate standard solution with carbontetrachloride. Azure-B $(0.1 \%)$ was prepared by dissolving $0.1 \mathrm{~g}$ of azure-B in $100 \mathrm{ml}$ of doubly - distilled water. $7.3 \mathrm{~g}$ of hydrogen phosphate monosodium were dissolved in distilled water and diluted to $100 \mathrm{ml}$ and adjusting with $\mathrm{HCl}$ followed by ammonia for phosphate buffer solution of $\mathrm{pH}$ 6.0. Freshly cut sodium metal $(1.0 \mathrm{~g})$ was dissolved in $100 \mathrm{ml}$ ethanol for $1 \%$ sodum ethoxide solution. This solution was prepared freshly.

\section{Procedure}

Standard dimethoate solution $(4.0-12.0 \mu \mathrm{g})$ dissolved in $\mathrm{CCl}_{4}$ was stabilized at room temperature by $1 \%$ sodium ethoxide solution to generate the corresponding sodium salt of dimethyl dithiophosphate (NaDMDTP). $10 \mathrm{ml}$ of aliquots of the standard dimethoate solution $(4.0-12.0 \mu \mathrm{g})$ and $2 \mathrm{ml}$ of $1 \%$ sodium ethoxide solution were taken in $100 \mathrm{ml}$ separating funnel. The mixture was swirled and allowed to stand for $30 \mathrm{~min}$. The mixture was acidified with $3 \mathrm{~N}$ nitric acid, $20 \mathrm{ml}$ of $\mathrm{CCl}_{4}$ was added and the mixture was shaken thoroughly for 2 to $3 \mathrm{~min}$ and allowed to separate. The $\mathrm{CCl}_{4}$ layer was discarded. This aqueous layer was washed with $\mathrm{CCl}_{4}$ until the $\mathrm{CCl}_{4}$ washings were colourless. To this aqueous layer, was added $10 \mathrm{ml}$ of $0.1 \%$ azure-B and $2 \mathrm{ml}$ of buffer solution of $\mathrm{pH} 6$. The solution in the separating funnel was shaken vigorously for $1 \mathrm{~min}$. The dimethyl-dithiophosphate (DMDTP) was complexed with cationic dye Na-DMDTP - azure-B was extracted as an ion-pair into chloroform. The scheme of hydrolysis of dimethoate and dimethoateazure-B complex was shown in Fig. 1a, $\mathbf{1 b}$.

\section{Determination of dimethoate in its formulations}

Dimethoate $30 \%$ EC was analysed using the aforesaid procedure by coupling cationic dye, azure-B. The method was compared with already reported literature ${ }^{11}$. Percentage recovery of dimethoate in 30 $\%$ EC was shown in Table 1.

\section{Determination of dimethoate in water samples}

The distilled tap water samples were fortified with the concentrations in the ranges of $0.2-2.2 \mathrm{ppm}$ in methanol which are given in the Table 2. The fortified water samples were extracted with chloroform. The combined extracts were washed with $0.1 \mathrm{M}$ potassium carbonate solution to break any emulsion formed during the extraction and dried over anhydrous sodium sulphate. Finally chloroform was evaporated to dryness on a steam bath and the residue was dissolved in methanol and the amount was determined using the procedure described earlier. 


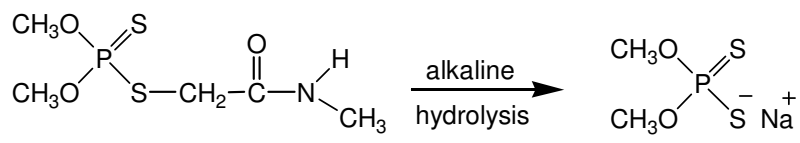

Fig 1.a Hydrolysis of dimethoate

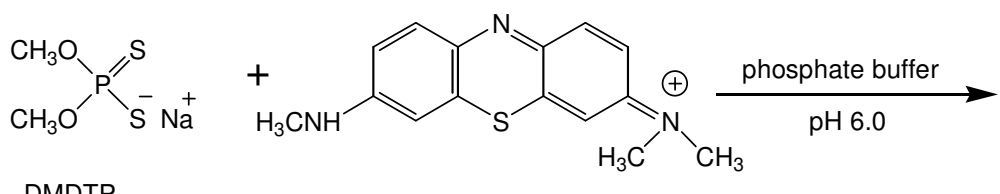

DMDTP

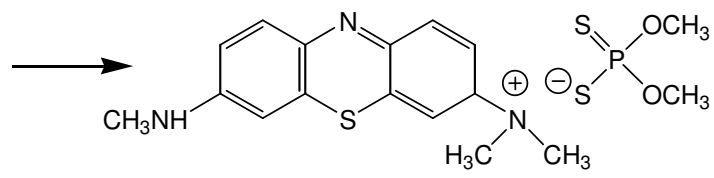

Fig 1.b Ion pair complex of dimethoate with aure-B

Table 1 Determination of dimethoate in insecticidal formulations using azure-B as complexing agent

\begin{tabular}{cc}
\hline S.No. & $\begin{array}{c}\text { Labelled Amount } \\
\mathbf{3 0 \%} \text { EC }\end{array}$ \\
\hline 1. & 29.80 \\
2. & 29.75 \\
3. & 29.65 \\
4. & 29.70 \\
5. & 29.75 \\
6. & 29.10 \\
${ }^{\mathrm{n}} \mathrm{n}=6$ &
\end{tabular}


Table 2 Recoveries of dimethoate residues from spiked water samples using azure-B as reagent

\begin{tabular}{cccccc}
\hline \multirow{2}{*}{ S.No. } & \multirow{2}{*}{$\begin{array}{c}\text { Fortification } \\
\text { level }(\mathrm{ppm})\end{array}$} & \multicolumn{2}{c}{ Tap Water } & \multicolumn{2}{c}{ Distilled Water } \\
\cline { 3 - 6 } & 0.6 & 0.58 & 96.66 & 0.57 & 95.00 \\
\hline 1. & 1.2 & 1.18 & 98.33 & 1.17 & 97.50 \\
2. & 1.8 & 1.78 & 98.88 & 1.76 & 97.77 \\
3. & 2.4 & 2.38 & 99.16 & 2.35 & 97.91 \\
4. & 3.0 & 2.98 & 99.33 & 2.95 & 98.33 \\
5. & 3.6 & 3.57 & 99.16 & 3.52 & 97.77 \\
6. & & & & & \\
\hline
\end{tabular}

\section{Determination of dimethoate in grain samples (wheat and rice)}

The grain samples (rice and wheat) of $50 \mathrm{~g}$ each were taken in warming blender and blended for 5 min with $100 \mathrm{ml}$ of chloroform. The samples were fortified with different concentrations of insecticides of dimethoate in methanol and blended for $3 \mathrm{~min}$. Chloroform was filtered and the residue was retained. The residue was washed twice with $10 \mathrm{ml}$ of chloroform and blended for 2 min.The chloroform extracts were evaporated on a steam bath and the residue was dissolved in methanol and the amount was determined by the procedure outlined earlier. The results were depicted in Table 3.

Table 3: Recoveries of dimethoate residues from grain samples using azure-B as reagent

\begin{tabular}{cccccc}
\hline \multirow{2}{*}{ S.No. } & \multirow{2}{*}{$\begin{array}{c}\text { Fortification } \\
\text { level }(\mathrm{ppm})\end{array}$} & \multicolumn{2}{c}{ Rice } & \multicolumn{2}{c}{ Wheat } \\
\cline { 3 - 6 } & 0.6 & 0.57 & 95.0 & 0.58 & 96.66 \\
\hline 1. & 1.2 & 1.19 & 99.16 & 1.18 & 98.33 \\
2. & 1.8 & 1.77 & 98.33 & 1.71 & 95.0 \\
3. & 2.4 & 2.36 & 98.33 & 2.32 & 96.66 \\
4. & 3.0 & 2.90 & 96.66 & 2.89 & 96.33 \\
5. & 3.6 & 3.57 & 99.16 & 3.53 & 98.05 \\
6. & & & & & \\
\hline
\end{tabular}

$\overline{\mathrm{a}}=6$.

\section{Results and Discussion}

Spectral Characteristics

Beer's Law is obeyed over the dimethoate concentration ranges over 0.4 to $12.0 \mu \mathrm{g} \mathrm{ml}^{-1}$. Limit of Quantification (LOQ) were determined by taking the standard deviation $(\sigma)$ of the blank with respect to water and slope of calibration curve is multiplied by a factor 10. That means, LOQ is approximately 3.3 times Limit of Detection (LOD). Normally the LOQ is slightly crosses the lower limit of Beer's law. But LOD is well below the limit of the Beer's law range. The upper limit of Beer Lambert law is determined by plot of absorbance against concentration at the value of $\lambda_{\max } 535 \mathrm{~nm}$. Beyond this limit, the correlation results were really affected. Hence the measurements were excluded above these limits to keep the linear relationship. The optical characteristics and precision data are presented in Table 4. 
Table 4 Optical characteristics precision and accuracy of the method using azure-B

\begin{tabular}{|c|c|}
\hline Analytical parameters & \\
\hline Concentration range $\left(\mu \mathrm{g} \mathrm{ml}^{-1}\right)$ & $0.4-12.0$ \\
\hline$\lambda_{\max }(\mathrm{nm})$ & 535 \\
\hline Colour & Blue \\
\hline Stability of color (h) & 7 days \\
\hline Molar absorptivity $\left(1 \mathrm{~mol}^{-1} \mathrm{~cm}^{-1}\right)$ & $6.217 \times 10^{4}$ \\
\hline Limit of detection $\left(\mu \mathrm{g} \mathrm{ml}^{-1}\right)$ & 0.627 \\
\hline Limit of quantification & 1.826 \\
\hline Sandell's sensitivity $\left(\mu \mathrm{g} \mathrm{cm}^{-2}\right)$ & 0.013 \\
\hline Relative standard deviation ${ }^{\mathrm{a}}$ & 1.36 \\
\hline \multicolumn{2}{|l|}{ Regression equation $(\mathrm{Y})^{\mathrm{a}}$} \\
\hline Slope $^{(\mathrm{b})}$ & $3.273 \times 10^{-2}$ \\
\hline Intercept ${ }^{(\mathrm{a})}$ & $4.281 \times 10^{-2}$ \\
\hline Correlation coefficient & 0.9992 \\
\hline Error \% & 1.25 \\
\hline
\end{tabular}

\section{Effect of $p H$}

Effect of $\mathrm{pH}$ on complexation of dimethyl dithiophosphate with Azure-B were studied. In order to determine the optimum $\mathrm{pH}$ value corresponding to maximum intensity of the colored complex, the complexation reaction was carried out in $p H$ range 4 to 8 using ELICO digital pH meter with combined glass electrode. The maximum color intensity was obtained at $p H 6.0$. So $p H 6.0$ was chosen as an optimum $\mathrm{pH}$ value for further studies.

\section{Effect of buffer}

Extraction of the ion - pair azure-B - NaDMTP was carried out in different buffer solutions with $p H$ 6 such as sulfuric acid- potassium dihydrogen phosphate, acetic acid - sodium acetate, ammonia hydrochloric acid and borax - hydrochloric acid. The absorbance intensity and complex stability (more than 7 days) in sulfuric acid - potassium dihydrogen phosphate of $p H 6$ is greater than in acetic acid - sodium acetate, ammonium - hydrochloride acid and borax - hydrochloride acid.

\section{Effect of solvent extraction}

Na-DMTP azure-B ion pair was studied in different organic solvents, such as chloroform, carbontetrachloride, cyclohexane, $\mathrm{n}$-hexane. The absorbance intensity was maximum in chloroform only and no absorbance intensity was detected in cyclohexane, n-hexane and carbontetrachloride. Hence chloroform was used as the most suitable solvent for the extraction of the DMTP - azure-B ion pair.

\section{Effect of Foreign Species and other Pesticides}

The effects of foreign species of other pesticides on the determination of dimethoate were studied. Known amounts of a variety of foreign speecis and pesticides were added to a standard solution containing $20 \mu \mathrm{g}$ of dimethoate in $25 \mathrm{ml}$. The solution were analysed by the proposed method. The results obtained are shown in Table 5. The results show that the foreign species and pesticides tested to not interfere in the analysis under the reported conditions. This indicates the validity of the method for the determination of dimethoate. 
Table 5 Effect of foreign species and other pesticides on the determination of dimethoate residues (concentration of dimethoate $20 \mu \mathrm{g} / 25 \mathrm{ml}$ )

\begin{tabular}{cccc}
\hline Foreign species & Tolerance & Pesticide & Tolerance \\
\hline $\mathrm{Ca}^{2+}$ & 200 & phenol & 250 \\
$\mathrm{Mg}^{2+}$ & 300 & Methyl parathion & 200 \\
$\mathrm{Cu}^{2+}$ & 200 & endosulfan & 200 \\
$\mathrm{Al}^{3+}$ & 350 & DDT & 250 \\
$\mathrm{Zn}^{2+}$ & 400 & Phorate & 200 \\
$\mathrm{NH}^{4+}$ & 300 & dichlorvos & 100 \\
$\mathrm{SO}_{4}^{2-}$ & 200 & & \\
$\mathrm{CO}_{3}^{2-}$ & 350 & & \\
$\mathrm{Cl}^{-}$ & 200 & & \\
\hline
\end{tabular}

*Tolerance limit, which caused up to $\pm 2 \%$ error in $\%$ recovery.

\section{Applications}

The proposed method was successfully employed for the determination of dimethoate in its formulation and various environmental samples. The results are summarised in Table $\mathbf{1}$ and $\mathbf{2}$. The results indicates that the present method is sensitive and selective when compared with reported method. ${ }^{11}$

\section{Conclusion}

The proposed method is simple, selective and highly sensitive than the reported method available in literature. ${ }^{11}$ The statistical parameter and recovery study data clearly indicates the reproducibility and accuracy of the method. Thus, the method can be adopted as an alternative to the existing spectrophotometric methods. Hence, recommended procedure is well suited for the analysis of organophosphorus pesticides in its formulations and various environmental samples.

\section{References}

1. Nag M and Nandi M, Indian J Exp Bio., 1987, 25, 567.

2. Narender S, J Indian Assoc Environ Management, 1990, 17, 26.

3. Kumar N V N and Bhaskar S U, J Food Sci Technol. 1980, 17, 153.

4. $\quad$ Bhaskar S U and Kumar N V N, Talanta, 1980, 27, 757.

5. Noble A, Walsh J J and Outhwaite R C, Pestic Sci, 1990, 29,387.

6. Yan Y Y, Fen His Husa Hsuesh, 1981, 9, 77.

7. Chen M and Wang Y, Fenxi Hauxue, 1984, 12, 300.

8. Miellet A, Ann Falsif, Exper. Chim. Toxicol, 1982, 75, 369.

9. Hanika G, Seifert K and Dorn U, Nehrung, 1989,33,1023.

10. Wang S, Chen H, Chen Z and Lu Y, Huanjing Wuran Yu Fangzhi,1987,9,39.

11. Ramamohan K, Ramesh A and Seshaiah K, Indian J Chem, 2000, 39A, 1331.

12. Rao A L J and Verma N, Indian J Forensic Sci, 1988, 2, 179. 


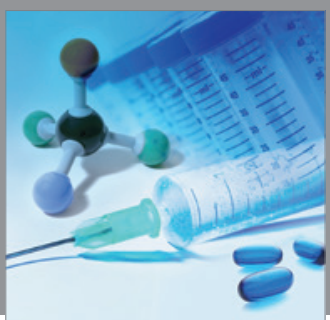

International Journal of

Medicinal Chemistry

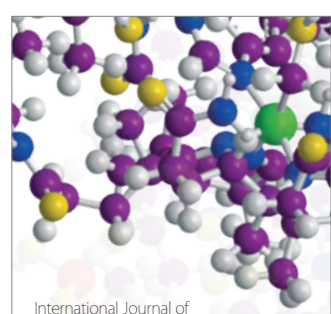

Carbohydrate Chemistry

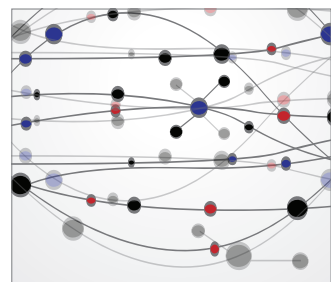

The Scientific World Journal
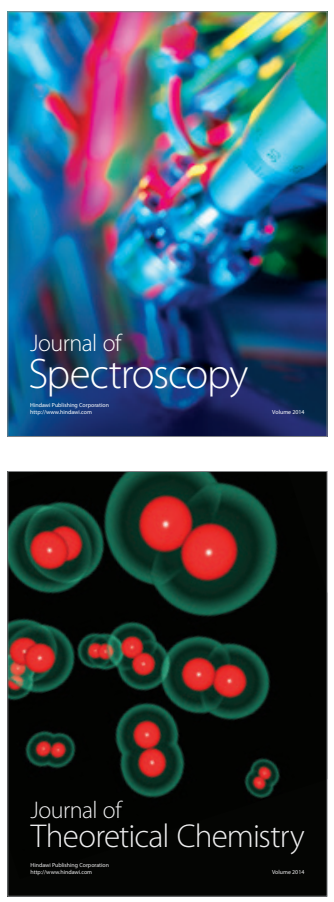
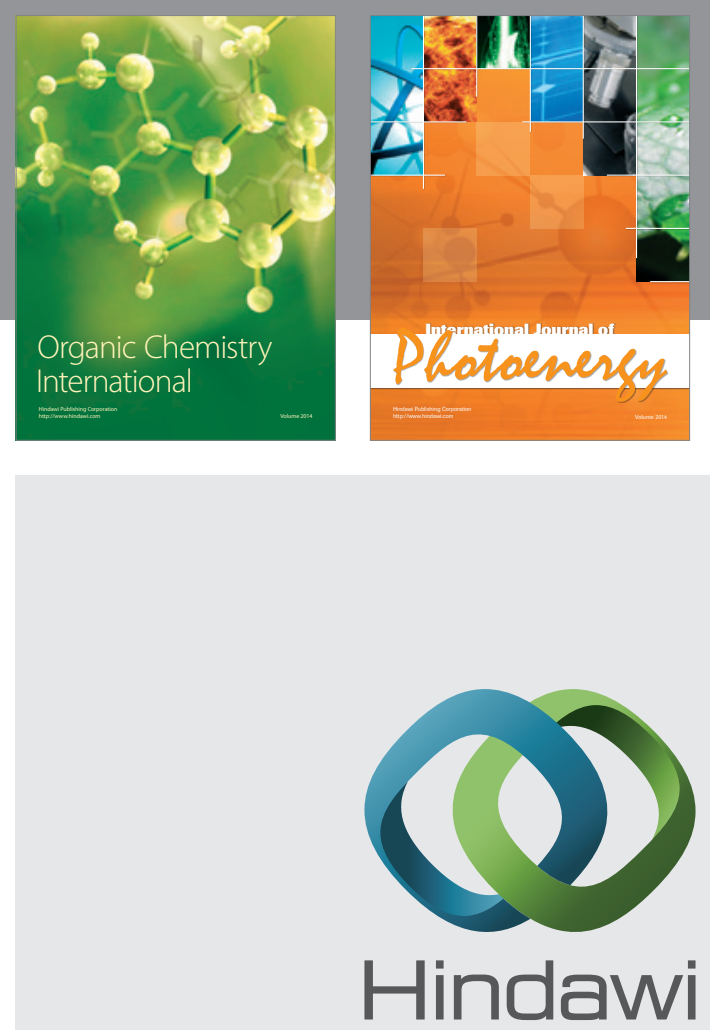

Submit your manuscripts at

http://www.hindawi.com
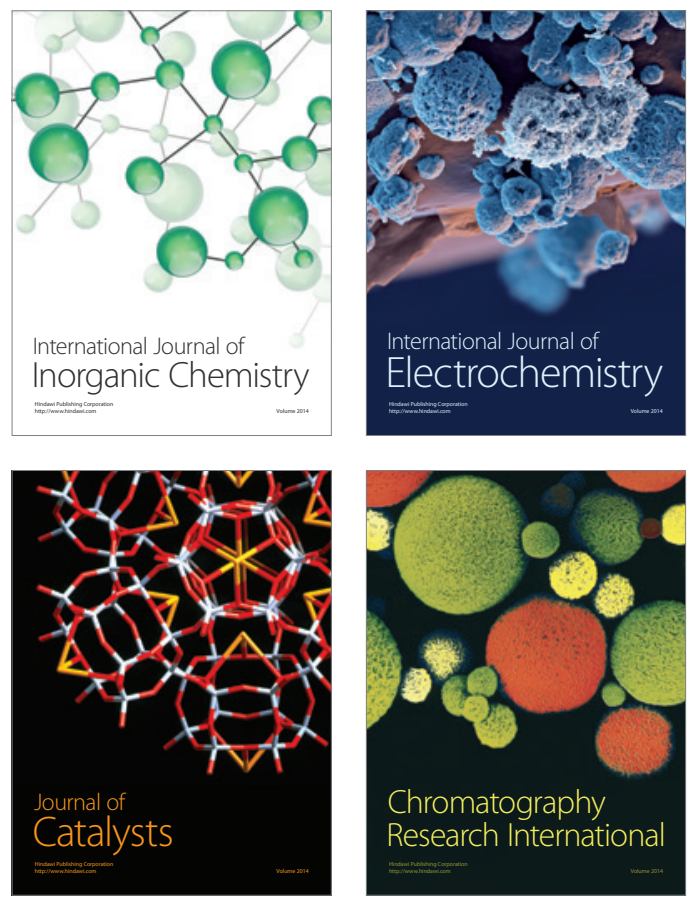
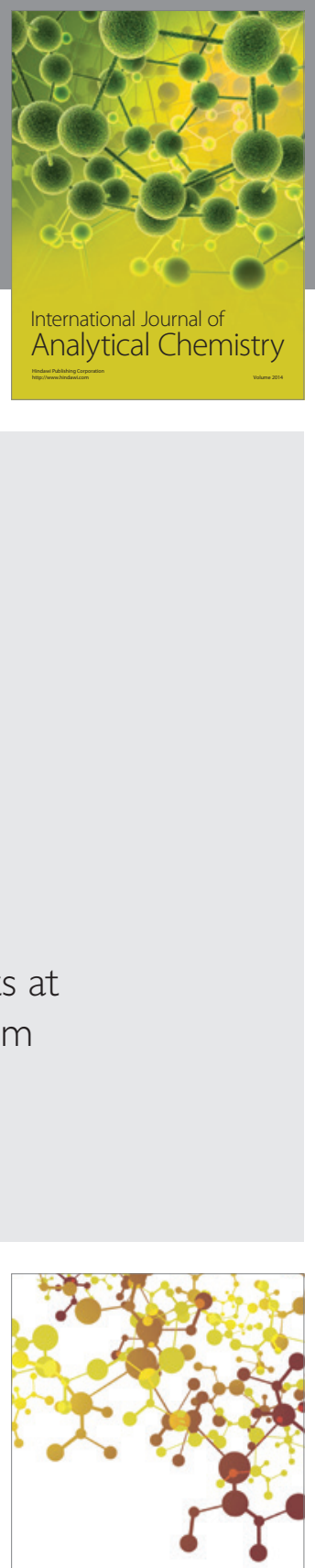

Journal of

Applied Chemistry
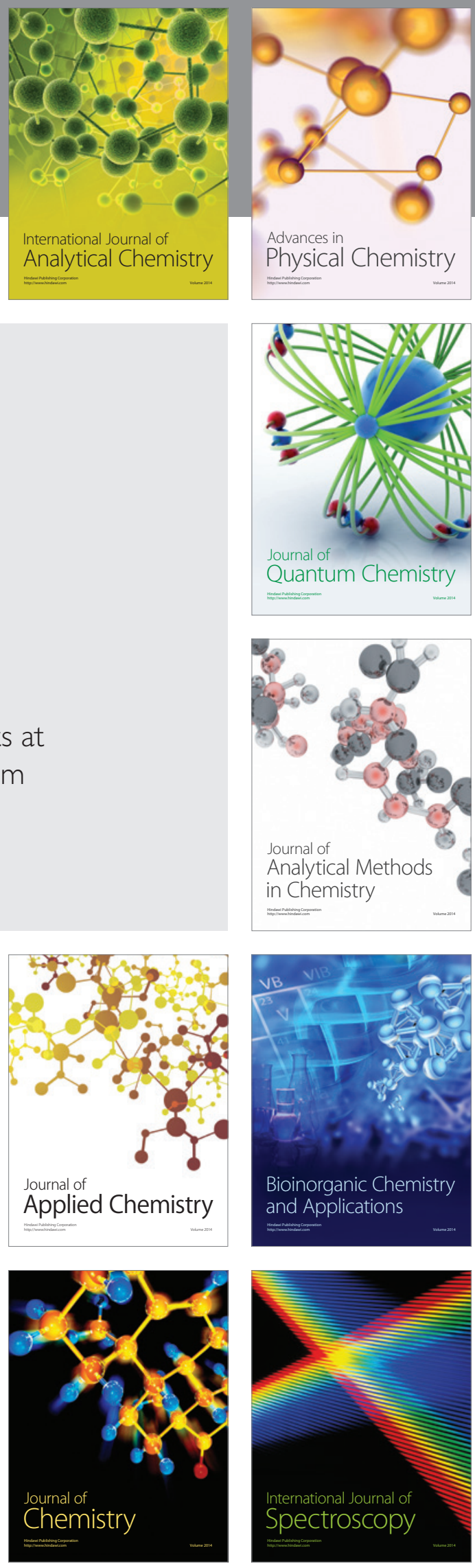